\title{
Bloodstream infections caused by multidrug-resistant gram-negative bacteria: epidemiological, clinical and microbiological features
}

Helena Ferreira Leal', Jailton Azevedo', Giulyana Evelyn Oliveira Silva², Angelica Maria Lima Amorim², Larissa Rangel Cabral de Roma², Ana Carolina Palmeira Arraes ${ }^{3}$, Edilane Lins Gouveia ${ }^{4}$, Mitermayer Galvão Reis ${ }^{1}$, Ana Verena Mendes ${ }^{3,5}$, Marcio de Oliveira Silva ${ }^{3}$, Maria Goreth Barberino ${ }^{3}$, lanick Souto Martins ${ }^{6}$ and Joice Neves Reis ${ }^{2^{*}}$ (D)

\begin{abstract}
Background: Bloodstream infections (BSI) are associated with high morbidity and mortality. This scenario worsens with the emergence of drug-resistant pathogens, resulting in infections which are difficult to treat or even untreatable with conventional antimicrobials. The aim of this study is to describe the epidemiological aspects of BSI caused by multiresistant gram-negative bacilli (MDR-GNB).

Methods: We conducted a laboratory-based surveillance for gram-negative bacteremia over a 1-year period. The bacterial isolates were identified by MALDI-TOF/MS and the antimicrobial susceptibility testing was performed by VITEK 2 . Resistance genes were identified through PCR assays.

Results: Of the 143 patients, 28.7\% had infections caused by MDR-GNB. The risk factors for MDR bacteremia were male sex, age $\geq 60$, previous antimicrobial use, liver disease and bacteremia caused by K. pneumoniae. K. pneumoniae was the most frequently observed causative agent and had the highest resistance level. Regarding the resistance determinants, SHV, TEM, OXA-1-like and CTX-M-gp1 were predominant enzymatic variants, whereas CTX-M-gp9, CTX-M-gp2, KPC, VIM, GES, OXA-48like, NDM and OXA-23-like were considered emerging enzymes.

Conclusions: Here we demonstrate that clinically relevant antibiotic resistance genes are prevalent in this setting. We hope our findings support the development of intervention measures by policy makers and healthcare professionals to face antibiotic resistance.
\end{abstract}

Keywords: Bacteremia, Antibiotic resistance, Gram-negative bacteria

\section{Background}

Bloodstream infections (BSI) are characterized as severe disorders since they are acute events and usually result in serious life-threatening organ dysfunctions, such as sepsis and septic shock [1,2]. Sepsis is considered to be a public health issue and is a leading cause of mortality worldwide, being recently listed as a global health priority

\footnotetext{
* Correspondence: joice@ufba.br

${ }^{2}$ Laboratory of Research on Clinical Microbiology (LPMC), School of

Pharmacy, Federal University of Bahia, Ondina, Salvador, Bahia 40170-115,

Brazil

Full list of author information is available at the end of the article
}

by World Health Organization [3, 4]. For dynamic infections such as BSI, the accurate diagnosis and administration of appropriate antimicrobial therapy are essential to enhance a patient's survivability, thereby reducing the high frequencies of morbidity and mortality [5-8].

Although the development of antimicrobial resistance control guidelines by healthcare agencies represents important measures to ensure patient care and to implement antimicrobial stewardship strategies, these should be personalized according to the background of each geographic location. Therefore, it is necessary to understand

(c) The Author(s). 2019 Open Access This article is distributed under the terms of the Creative Commons Attribution 4.0 International License (http://creativecommons.org/licenses/by/4.0/), which permits unrestricted use, distribution, and reproduction in any medium, provided you give appropriate credit to the original author(s) and the source, provide a link to the Creative Commons license, and indicate if changes were made. The Creative Commons Public Domain Dedication waiver (http://creativecommons.org/publicdomain/zero/1.0/) applies to the data made available in this article, unless otherwise stated. 
local epidemiology through clinical and microbiological monitoring [9-11].

The epidemiology of BSI has been described extensively in many different countries [12-16]. However, when coming to the antibiotic resistance issue, only a few investigations conduct further research into detecting resistance genes [15, 17]. Likewise, many studies tackling the antibiotic resistance rely on the problem of screening resistant isolates solely, which may substantially affect susceptibility reports, representing a strong bias towards resistance [18].

In order to provide epidemiological and microbiological information about the occurrence of BSI due to gram-negative-bacilli (GNB), we conducted a prospective laboratory-based surveillance for BSI caused by GNB from 2015 through 2016 in tertiary referral hospital in the city of Salvador. Not only we expect that the evidence presented here give rise to intervention strategies for effective antimicrobial therapy, but also foster early measures to control the spread of MDR-GNB.

\section{Methods}

\section{Study design and population}

A prospective surveillance of patients with positive blood culture was conducted at the São Rafael Hospital (HSR) from March 2015 to March 2016. The HSR addresses medium and high complexity procedures. The population studied was composed of patients without age restriction with BSI due to GNB, defined by positive blood culture with signs and symptoms of infection. Epidemiological and clinical characteristics of patients with BSI caused by S-GNB and MDR-GNB were compared.

\section{Data collection and definitions}

Demographic and clinical data was collected through a review of medical records. The clinical characteristics addressed included: hospitalization unit, hospitalization during the previous 6 months, previous healthcare assistance, previous infections, comorbidities, presented symptoms, possible sources and risk factors for bacteremia, use of antibiotics in the previous 6 months, empirical and culture-guided therapy and clinical outcome in 30 days. The Charlson comorbidity index was used to measure the severity of underlying conditions at the time of admission, and the severity of the BSI episode was measured using the Pitt bacteremia score $[19,20]$.

The location of acquisition and type of BSI were defined as follows: 1) "community-onset - healthcareassociated" (CO-HCA) was defined as a BSI occurring within $48 \mathrm{~h}$ of hospital admission plus the presence of one of the following healthcare risk factors: prior hospitalization, surgery, dialysis, or residence in a longterm care facility within the 12 months preceding the
BSI, or the presence of an invasive device; 2) "community-acquired" (CA) was defined as a BSI occurring $\leq 48$ $\mathrm{h}$ after admission but without one of the above healthcare risk factors; and 3) "hospital-onset-healthcare-associated" (HO-HCA) was defined as a BSI that occurred $48 \mathrm{~h}$ after hospital admission [12, 21].

The BSI episodes were also classified by their origin in primary and secondary infections. Primary BSI is laboratory-confirmed by positive blood culture, but it has no identifiable extravascular focus of infection. Secondary BSI is characterized by the occurrence of a positive blood culture or clinical signs of sepsis in the presence of infection elsewhere [22, 23].

The conditions of sepsis, severe sepsis and septic shock have been identified using definitions established by the 1991 Consensus Conference, which were updated in 2001 [24, 25]. The multidrug resistance phenotype was defined using the consensus definitions proposed by Magiorakos et al. [26]. Episodes of polymicrobial infections were those in which more than one species were found in the same blood culture.

\section{Microbial isolation and identification and antimicrobial susceptibility testing}

The blood cultures were performed on BacT/ALERT ${ }^{\circ}$ 3D (bioMeriéux-France) and microbial identification was performed by MALDI-TOF MS (bioMeriéux-France) as described by Barberino et al. [27]. All GNB identified were stored in Trypticase Soy Broth (TSB) enriched with $10 \%$ glycerol at $-70{ }^{\circ} \mathrm{C}$ until it was reactivated for molecular tests.

The antimicrobial susceptibility profile of the enterobacteria was determined using a VITEK $2^{\circ}$ (bioMeriéuxFrance). For non-fermentative GNB, antibiograms were manually performed using the agar-diffusion technique. The tests and the interpretative criteria were performed according to Clinical and Laboratory Standard Institute recommendations [28].

\section{Detection of antimicrobial resistance encoding genes}

DNA extraction was performed from bacterial colonies cultured in TSA (Tryptic Soy Agar) for 18 to $24 \mathrm{~h}$ at $36^{\circ} \mathrm{C}$. The colonies were resuspended in $100 \mu \mathrm{l}$ of sterile MilliQ water and heated at $95^{\circ} \mathrm{C}$ for a period of $10 \mathrm{~min}$. Subsequently, the content was centrifuged at $12,000 \mathrm{rpm}$ for $2 \mathrm{~min}$. The supernatant containing the genetic material was transferred to a sterile tube and stored at $-20{ }^{\circ} \mathrm{C}$ until PCR was performed.

Four multiplex PCR reactions were performed using the primer sequence and protocol developed by Dallene et al. [29] for the $b l a_{\mathrm{TEM}}, b l a_{\mathrm{SHV}}$, and $b l a_{\mathrm{OXA}-1-}$ like genes; the $b l a_{\mathrm{CTX}-\mathrm{M}}$ (group $1,2,9$ ); the $b l a_{\mathrm{GES}}$ and $b l a_{\mathrm{OXA}-48-\mathrm{like}} ;$ and $b l a_{\mathrm{KPC}}$ and $b l a_{\mathrm{VIM}}$. In addition, three simplex reactions were performed to detect the 
presence of $b l a_{\mathrm{IMB}}, b l a_{\mathrm{NDM}}$ and $b l a_{\mathrm{OXA}-23-\text { like }}$ genes using the primer sequences and protocol proposed by van der Zwaluw et al. [30] (Additional file 1: Table S1). The positive controls were bacterial DNA extracts from reference strains (Additional file 2: Table S2). The PCR products were electrophoresed as described by the two mentioned authors.

\section{Data management and statistical analyses}

The data was managed and analyzed using Epi Info version 3.5.1 (CDC, Atlanta, GA, USA). For the epidemiological analysis, duplicate cases (i.e. patients who had experienced two episodes of BSI within 30 days and patients with polymicrobial infections) were excluded, so the episodes were analyzed based on the first entry.

Fisher's exact or chi-square tests were used to compare the differences between the proportions for dichotomous variables, and the odds ratio (OR) and 95\% confidence interval (CIs) were calculated as measures of association. Statistical significance was defined as $P<0.05$. A multivariate logistic regression analysis was performed to identify the independent risk factors for MDR-GNB bacteremia. The variables introduced into the model included those with a crude $P$-value of $<0.25$, those that were biologically sound, and those found in previous studies of BSI and MDR infections. We used backward elimination of any confounding variable based on the likelihood ratio test, using a significance cutoff of 0.05 .

\section{Results}

During the study period, 143 patients with bacteremia due to GNB were identified. Most of the patients were male $(88,61.5 \%)$ and were 60 years or older $(73,51.0 \%)$. The characteristics of the case patients are shown in Table 1.

Regarding the characteristics of the BSI episodes, most infections were primary 80/143 (55.9\%). Among the secondary cases, the urinary tract $(20.3 \%)$ was the most frequent site of origin, followed by the respiratory tract (11.8\%). Concerning the location of acquisition, 93 (65.0\%) episodes were $\mathrm{HO}-\mathrm{HCA}, 44(30.8 \%)$ were COHCA, and $6(4.2 \%)$ were CA. The original site of the infection and the location of acquisition were not associated with the presence of the MDR pathogen.

Among the patients with CO-HCA infections $(n=44)$, the healthcare risk factors were a previous admission $(n=32)$, hemodialysis $(n=8)$, previous invasive procedure $(n=6)$, chemotherapy $(n=5)$ and homecare $(n=6)$. Among the patients with HO-HCA infections, the hospital settings in which they were allocated were hospital wards $(n=50)$, followed by the intensive care unit $(n=25)$, semi intensive care unit $(n=13)$ and emergency department $(n=2)$.

\section{Risk factors for MDR bacteremia}

Among 143 episodes of BSI, 41 (28.7\%) were caused by MDR-GNB. Univariate analysis performed to investigate the possible risk factors associated with $\mathrm{BSI}$ caused by MDR-GNB is presented in Table 1 and Table 2. Regarding the comorbidities addressed by the Charlson score, liver disease was positively associated with the presence of MDR pathogens. In addition, male sex, age $\geq 60$ and the previous use of antimicrobial showed positive associations also.

Upon stratifying the previous use of antimicrobials in prophylactic and therapeutic, the statistical significance solely remained for the therapeutic use. Regarding the class of drugs used therapeutically, we found the use of fluoroquinolones and folate pathway inhibitors were more frequent in the MDR group $(6,23.1 \%$ vs. $4,9.3 \%$ in the non-MDR group). However, this difference was not statistically significant $(P=0.24)$.

Concerning the etiology, K. pneumoniae infections had a positive association with the MDR phenotype $(P<0.05)$. Although Acinetobacter baumannii was more frequent in the MDR group than in the non-MDR group ( $8.2 \%$ vs. $1.7 \%)$, the statistical significance was not reached $(P=0.06)$. The presence of infections caused by Serratia marcescens, as well as the infections caused by the less frequently isolated bacteria (which were categorized into the "others" group), were negatively associated with the MDR phenotype.

Infections caused by MDR pathogens culminated in BSIs with high severity (Table 2). This association can be verified through the Pitt score, which was higher in patients with MDR infections (median 5 vs. median $2, P=0.07$ ) as well as the number of patients who experienced systemic complications due to bacteremia, such as severe sepsis and septic shock (65.9\% vs. $48.0 \%)$. These indicators of severity were more frequent among MDR cases; however, it is important to clarify that none of these associations reached statistical significance. Infections caused by MDR pathogens were associated with death $(P<0.001)$ (Table 2$)$.

A multivariate logistic regression was used to identify the factors that were independently associated with MDR infections. The results are shown in Table 3.

Among all the analyzed factors, male sex $(P=0.02)$, age $\geq 60$ years old $(P=0.03)$, previous therapeutic antimicrobial use $(P=0.04)$, liver disease $(P=0.02)$ and bacteremia by $K$. pneumoniae $(P=0.0006)$ were associated with the presence of MDR infections. Among these factors, we can highlight the bacteremia from $K$. pneumoniae and liver disease, since patients with these characteristics had 4.6 and 4.9 times greater odds of presenting MDR infections than those who did not.

\section{Microbiological features}

Of the 143 patients with BSI, a total of 170 bacterial isolates were recovered. Enterobacteriaceae were 
Table 1 Epidemiological, demographic and clinical characteristics of patients with bloodstream infections (BSI) caused by gramnegative bacteria in tertiary referral hospital in Salvador, Brazil $(n=143)$

\begin{tabular}{|c|c|c|c|c|}
\hline Characteristics & $\begin{array}{l}\text { MDR } \\
n(\%) \\
n=41(28.7)\end{array}$ & $\begin{array}{l}\text { Non-MDR } \\
n(\%) \\
n=102(71.3)\end{array}$ & $p$-value & OR $(95 \% \mathrm{Cl})$ \\
\hline \multicolumn{5}{|l|}{ Demographic data } \\
\hline Male sex & $31(75.6)$ & $57(55.9)$ & 0.03 & $2.45(1.09-5.52)$ \\
\hline Age groups (years), median (1 qt-3 qt) & $63(51-72)$ & $57(38-69)$ & $0.03^{+}$ & - \\
\hline $0-15$ & $0(0.0)$ & $6(5.9)$ & 0.12 & - \\
\hline $16-30$ & $4(9.8)$ & $11(10.8)$ & 0.56 & $0.89(0.26-2.99)$ \\
\hline $31-59$ & $11(26.8)$ & $38(37.3)$ & 0.23 & $0.61(0.28-1.37)$ \\
\hline$\geq 60$ & $26(63.4)$ & $47(46.1)$ & 0.06 & $2.02(0.96-4.27)$ \\
\hline \multicolumn{5}{|l|}{ Comorbidities } \\
\hline Charlson score, median (1 qt-3 qt) $(n=134)^{*}$ & $2.5(2-4)$ & $2(2-3)$ & 0.10 & - \\
\hline$\geq 2(n=134)$ & $20(50.0)$ & $39(41.5)$ & 0.37 & $1.41(0.67-2.97)$ \\
\hline Congestive heart failure $(n=134)$ & $3(7.5)$ & $5(5.3)$ & 0.45 & $1.44(0.33-6.35)$ \\
\hline Cerebrovascular disease $(n=134)$ & $5(12.5)$ & $11(11.7)$ & 0.55 & $1.08(0.35-3.33)$ \\
\hline Liver disease & $7(17.5)$ & $5(5.3)$ & 0.02 & $3.78(1.12-12.73)$ \\
\hline Kidney disease & $6(15.0)$ & $21(22.3)$ & 0.33 & $0.61(0.23-1.66)$ \\
\hline History of malignancy & $16(40.0)$ & $42(44.7)$ & 0.62 & $0.82(0.39-1.76)$ \\
\hline Metastatic disease & $7(17.5)$ & $16(17.0)$ & 0.95 & $1.03(0.39-2.75)$ \\
\hline HIV/AIDS & $1(2.5)$ & $0(0.0)$ & 0.12 & - \\
\hline Previous antimicrobial use $(n=80)$ & $29(70.7)$ & $51(50.0)$ & 0.02 & $2.41(1.11-5.25)$ \\
\hline Prophylactic & $8(19.5)$ & $21(20.6)$ & 0.88 & $0.93(0.37-2.32)$ \\
\hline Therapeutic & $26(63.4)$ & $43(42.2)$ & 0.02 & $2.37(1.12-5.02)$ \\
\hline \multicolumn{5}{|l|}{ Clinical information } \\
\hline Hospitalized in prior 6 months $(n=140)$ & $26(65.0)$ & $54(54.0)$ & 0.24 & $1.58(0.74-3.38)$ \\
\hline Long hospital stay (> 14 days) & $30(73.2)$ & $70(68.6)$ & 0.59 & $1.2(0.55-2.79)$ \\
\hline Users of Health Insurance & $31(75.6)$ & $73(71.6)$ & 0.62 & $1.23(0.54-2.94)$ \\
\hline \multicolumn{5}{|l|}{ Type of BSI } \\
\hline Primary & $24(58.5)$ & $56(54.9)$ & 0.69 & $1.16(0.56-2.41)$ \\
\hline Secondary $(n=63)$ & $17(41.5)$ & $46(45.1)$ & 0.69 & $1.16(0.56-2.41)$ \\
\hline Urinary tract $(n=29)$ & $7(41.2)$ & $22(45.8)$ & 0.74 & $0.82(0.27-2.53)$ \\
\hline Respiratory tract $(n=17)$ & $5(29.4)$ & $12(25.0)$ & 0.72 & $1.25(0.37-4.28)$ \\
\hline Others $(n=19)$ & $5(29.4)$ & $14(29.2)$ & 0.98 & $1.02(0.30-3.41)$ \\
\hline \multicolumn{5}{|l|}{ Location of acquisition } \\
\hline Community-associated $(n=6)$ & $1(2.4)$ & $5(4.9)$ & 0.45 & $0.48(0.05-4.28)$ \\
\hline Community-onset, healthcare associated $(n=44)$ & $11(26.8)$ & $33(32.4)$ & 0.51 & $0.76(0.34-1.71)$ \\
\hline Hospital-onset, healthcare associated $(n=93)$ & $29(70.7)$ & $64(62.7)$ & 0.36 & $1.43(0.65-3.14)$ \\
\hline \multicolumn{5}{|l|}{ Organisms $(n=170)^{* *}$} \\
\hline Escherichia coli $(n=50)$ & $12(24.5)$ & $38(31.4)$ & 0.37 & $0.70(0.33-1.50)$ \\
\hline Klebsiella pneumoniae $(n=50)$ & $27(55.1)$ & $23(19.0)$ & $<0.001$ & $5.23(2.53-0.77)$ \\
\hline Serratia marcescens $(n=15)$ & $1(2.0)$ & $14(11.6)$ & 0.04 & $0.15(0.02-1.24)$ \\
\hline Enterobacter cloacae $(n=13)$ & $3(6.1)$ & $10(8.3)$ & 0.45 & $0.72(0.19-2.75)$ \\
\hline Pseudomonas aeruginosa $(n=12)$ & $2(4.1)$ & $10(8.3)$ & 0.28 & $0.47(0.09-2.24)$ \\
\hline Acinetobacter baumannii $(n=6)$ & $4(8.2)$ & $2(1.7)$ & 0.06 & $5.29(0.93-9.88)$ \\
\hline Others*** $(n=24)$ & $0(0)$ & $24(19.8)$ & $<0.001$ & - \\
\hline
\end{tabular}


Table 1 Epidemiological, demographic and clinical characteristics of patients with bloodstream infections (BSI) caused by gramnegative bacteria in tertiary referral hospital in Salvador, Brazil $(n=143)$ (Continued)

\begin{tabular}{lllll}
\hline Characteristics & MDR & Non-MDR & P-value & OR (95\% CI) \\
& $\begin{array}{l}n(\%) \\
n=41(28.7)\end{array}$ & $n=102(71.3)$ & & \\
\hline Polymicrobial BSI $(n=22)^{\Omega}$ & $9(18.4)$ & $13(10.7)$ & 0.18 & $1.87(0.74-4.71)$ \\
\hline
\end{tabular}

$\left(^{+}\right)$Mann-Whitney U Test; $(-)$Not calculated; $\left(^{*}\right)$ Of the 143 patients, 134 had comorbidities according to their Charlson's score. Regarding diabetes, diabetes with any organ demage, myocardial infarction, peripheral vascular disease, dementia, chronic obstructive pulmonary disease, connective tissue disease, peptic ulcer, hemiplegia or paraplegia and HIV/AIDS data are not shown since the number of patients with those comorbidities were limited $(n<5)$. None of the mentioned illnesses were risk or protective factor for MDR infection; $\left.{ }^{* *}\right)$ considering all isolates recovered; $\left.{ }^{* * *}\right)$ Aeromonas hydrophila $(n=4)$, Burkholderia cepacia $(n=1)$, Citrobacter koseri $(n=1)$, Elizabethkingia meningoseptica $(n=1)$, Enterobacter aerogenes $(n=2)$, Klebsiella oxytoca $(n=1)$, Moraxella osloensis $(n=1)$, Proteus mirabilis $(n=4)$, Pseudomonas putida $(n=1)$, Salmonella spp. $(n=1)$, Sphingomonas paucimobilis $(n=1)$, and Stenotrophomonas malthophilia $(n=6) ;(\Omega)$ in the study period 11 polymicrobial episodes were identified, and they involved 22 microbial isolates

predominant $(n=137,80.5 \%)$ with Escherichia coli $(n=50)$ and K.pneumoniae $(n=50)$ being most frequently isolated. Among the non-fermentative GNB isolated $(n=29,16.4 \%)$, Pseudomonas aeruginosa $(n=12)$, A. baumannii $(n=6)$ and Stenotrophomonas maltophilia $(n=6)$ were the most frequently observed pathogens (Table 1).

When we stratified the pathogens based on their location of acquisition (Fig. 1), it was noted that the CA group consisted of E. coli $(n=3), K$. pneumoniae $(n=2)$ and $S$. marcescens $(n=1)$ infections. Regarding the diversity of pathogens, the HO-HCA infections were the most heterogeneous, with K. pneumoniae (30/93, 32.3\%) being the most frequently observed microorganism. It is noteworthy that the infections caused by $A$. baumannii occurred only in this group. For CO-HCA infections, it is also possible to see a greater diversity of pathogens, but, similar to CA, the most frequently noted microorganism was $E$. coli $(21 / 44,47.7 \%)$.

While stratifying the etiology of cases per months, no clusters were observed. The pathogen distribution occurred equally during the months of the study. Upon correlating the etiology and hospitalization units, E. coli and $K$. pneumoniae cases were present in all them; however, there was a predominance of $K$. pneumoniae in the intensive care unit (ICU) and $E$. coli in the hospital wards and emergency department.

The proportion of antimicrobial resistance among Enterobacteriaceae that were most frequently isolated can be seen in Table 4. K. pneumoniae had the highest resistance levels, including penicillins associated with $\beta$ lactamase inhibitors (52.0-62.0\%), cephalosporins (50.0$52.0 \%)$, carbapenems (10.0\%), fluoroquinolones (46.0\%) and aminoglycosides (2.0-28.0\%). It is noteworthy that two $K$. pneumoniae isolates were resistant to polymyxin. This resistance was initially detected by the VITEK $2^{\circ}$ (bioMeriéux-France) and by E-test (bioMeriéux-France). However, this phenotype was confirmed by broth microdilution for only one isolate (minimum inhibitory concentration of $64 \mu \mathrm{g} / \mathrm{mL}$ ).

Regarding the antimicrobial resistance frequency for the non-fermentative GNB (Table 5), A. baumannii presented very high levels of resistance when compared to P.aeruginosa, highlighting the resistance to

Table 2 Clinical and prognostic characteristics of patients with bloodstream infections (BSI) caused by gram-negative bacteria in tertiary referral hospital in Salvador, Brazil $(n=143)$

\begin{tabular}{|c|c|c|c|c|}
\hline Characteristics & $\begin{array}{l}\text { MDR } \\
n(\%) \\
n=41(28.7)\end{array}$ & $\begin{array}{l}\text { Non-MDR } \\
n(\%) \\
n=102(71.3)\end{array}$ & $p$-value & OR $(95 \% \mathrm{Cl})$ \\
\hline \multicolumn{5}{|l|}{ Potential risk factors } \\
\hline Catheter use $(n=58)$ & $15(51.7)$ & $43(71.7)$ & 0.06 & $0.42(0.16-1.06)$ \\
\hline Ventilator $(n=21)$ & $5(17.2)$ & $16(26.7)$ & 0.32 & $0.57(0.18-1.75)$ \\
\hline \multicolumn{5}{|l|}{ Severity of illness } \\
\hline Pitt score, median (1 qt-3 qt) & $5(1-10)$ & $2(0-6)$ & $0.07^{\mathrm{a}}$ & - \\
\hline 0 & $8(21.6)$ & $33(31.1)$ & 0.27 & $0.61(0.25-1.48)$ \\
\hline 1 & $6(40.0)$ & $35(27.3)$ & 0.31 & $1.77(0.59-5.34)$ \\
\hline $2-3$ & $4(14.3)$ & $37(32.2)$ & 0.06 & $0.35(0.11-1.09)$ \\
\hline$\geq 4$ & $23(36.5)$ & $18(22.5)$ & 0.06 & $1.9(0.95-4.12)$ \\
\hline Severe sepsis or septic shock $(n=76)$ & $27(65.9)$ & $49(48.0)$ & 0.06 & $2.09(0.99-4.43)$ \\
\hline Crude mortality & $23(56.1)$ & $27(26.5)$ & $<0.001$ & $3.5(1.65-7.62)$ \\
\hline
\end{tabular}

${ }^{(a)}$ Mann-Whitney U Test; $\left({ }^{b}\right)$ Sepsis complicated by organ dysfunction is termed severe sepsis, which could progress to septic shock, which is defined as "sepsisinduced hypotension persisting despite adequate fluid resuscitation" 
Table 3 Adjusted odds ratio for independent risk factors for multidrug resistant gram-negative bacteremia based on multivariate logistic regression analysis ${ }^{a}$

\begin{tabular}{lll}
\hline Risk factors & \multicolumn{2}{l}{ Adjusted multivariate } \\
\cline { 2 - 3 } & p-value & OR $(95 \% \mathrm{Cl})$ \\
\hline Male sex & 0.02 & $2.98(1.18-7.47)$ \\
Age $\geq 60$ years old & 0.03 & $2.52(1.07-5.93)$ \\
Previous therapeutic antimicrobial use & 0.04 & $2.45(1.06-5.65)$ \\
Liver disease & 0.02 & $4.91(1.25-19.29)$ \\
Bacteremia by Klebsiella pneumoniae & $<0.001$ & $4.59(1.93-70.93)$ \\
\hline
\end{tabular}

(') Multivariate analysis using a logistic regression model included the following variables: male sex, age $\geq 60$ years old, previous therapeutic antimicrobial use, liver disease, catheter use, hospitalization in prior 6 months and bacteremia by K. pneumoniae

penicillins associated with $\beta$-lactamase inhibitors, cephalosporins, carbapenems (66.7\%) and folate pathway inhibitors (83.4\%). However, all A. baumannii isolates were full susceptible against tigecycline.

Of the 170 microorganisms isolated, 158 were subjected to PCR for the detection of resistance genes, of which $84(53.2 \%)$ were positive for at least one of the tested genes. $K$. pneumoniae was the species with the highest prevalence of resistance genes $(74.0 \%)$, followed by E. coli (60.0\%), P. mirabilis (50.0\%), E. cloacae
(46.2\%), A. baumannii, (33.3\%), Aeromonas hydrophila (25.0\%) and $P$. aeruginosa (8.3\%).

The $b l a_{\mathrm{SHV}}$ gene was found in $n=42$ isolates, with bla $a_{\mathrm{TEM}}$ in $n=37$; bla $a_{\mathrm{OXA}-1 \text {-like }}$ in $n=22$; bla $a_{\mathrm{CTX}-\mathrm{M}-\mathrm{gp} 1}$ in $n=22 ; b l a_{\mathrm{KPC}}$ in $n=5 ; b l a_{\mathrm{CTX}-\mathrm{M}-\mathrm{gp} 9}$ in $n=4$; bla $a_{\mathrm{CTX}-\mathrm{M}-\mathrm{gp} 2}, b l a_{\mathrm{VIM}}, b l a_{\mathrm{GES}}, b l a_{\mathrm{OXA}-48-\text { like }}, b l a_{\mathrm{NDM}}$; and

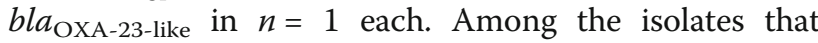
caused CA infections, $n=3(50 \%)$ presented resistance genes $\left(b l a_{\mathrm{TEM}}, b l a_{\mathrm{SHV}}\right.$, and $\left.b l a_{\mathrm{CTX}-\mathrm{M} \text {-gp } 9}\right)$.

The maximum number of different resistance genes found in a single isolate was $n=5$ in a $K$. pneumoniae isolate. Isolates of the same species with similar genetic determinants of resistance were considered as having the same genetic profile. A total of 37 genetic profiles and their description can be found in Additional file 3: Table S3. The distribution of antimicrobial resistance encoding genes stratified by pathogens is shown in Additional file 4: Figure S1.

Among the $30 \mathrm{E}$. coli isolates and the $37 \mathrm{~K}$. pneumoniae isolates positive for at least one resistance gene, 10 and 14 genetic resistance profiles were found, respectively. Those profiles were distributed over time (study period in months) and space (hospital units). Regarding $E$. coli, it was noted that the most frequently observed genetic profile, i.e., the one present in a greater number of isolates $\left(1 e-b l a_{\mathrm{TEM}}, n=18\right)$, was prominent during the

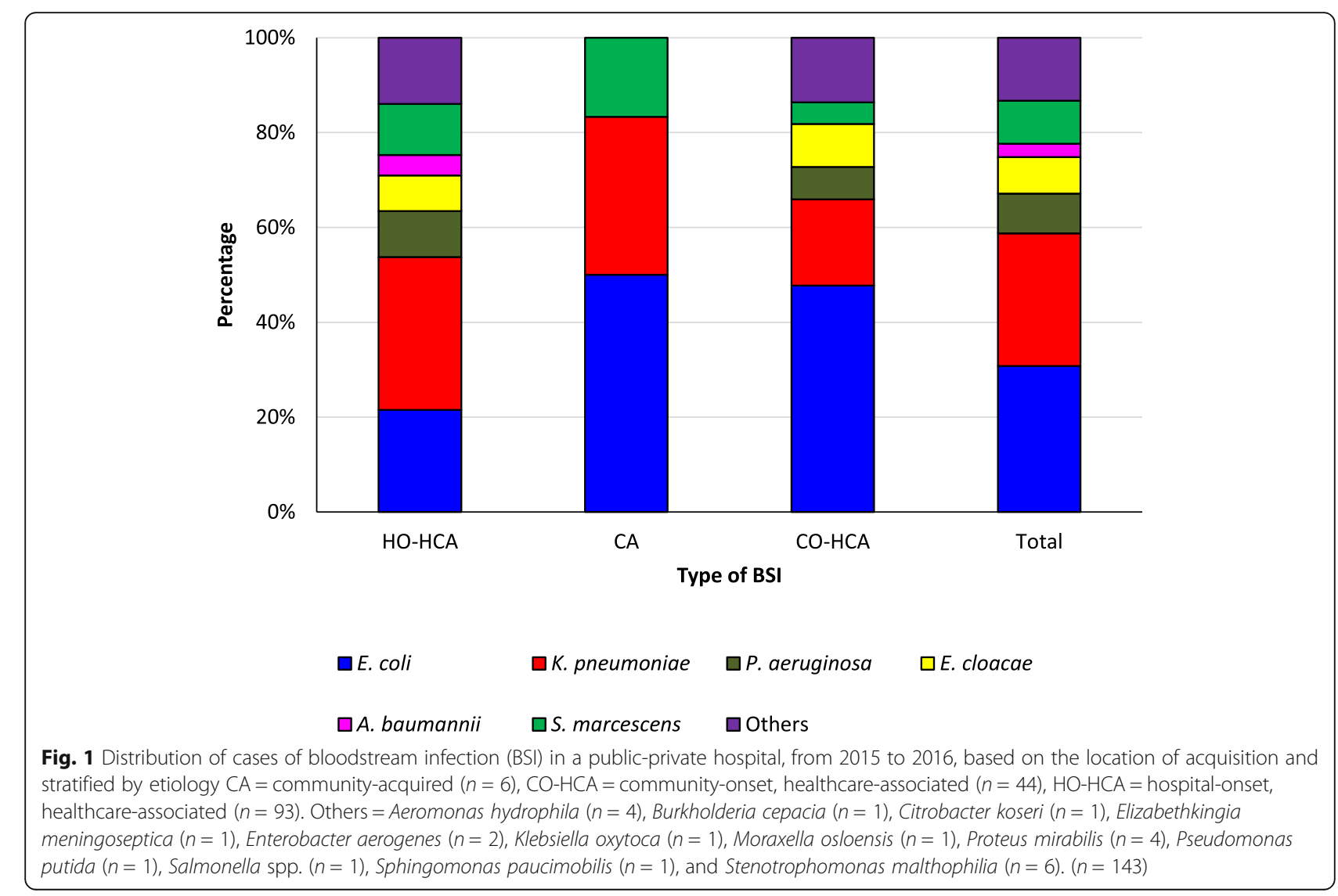


Table 4 Proportions of antimicrobial resistance among Enterobacteriaceae that were most frequently isolated from bloodstream infections

\begin{tabular}{|c|c|c|c|c|c|c|c|c|}
\hline \multirow[b]{2}{*}{ Antimicrobial drug } & \multicolumn{2}{|l|}{$\begin{array}{l}\text { Escherichia coli } \\
(n=50)\end{array}$} & \multicolumn{2}{|c|}{$\begin{array}{l}\text { Klebsiella pneumoniae } \\
(n=50)\end{array}$} & \multicolumn{2}{|c|}{$\begin{array}{l}\text { Serratia marcescens } \\
(n=50)\end{array}$} & \multicolumn{2}{|c|}{ Enterobacter cloacae $(n=13)$} \\
\hline & No. of isolates & $\%$ resistant* & No. of isolates & $\%$ resistant* & No. of isolates & $\%$ resistant* & No. of isolates & $\%$ resistant* \\
\hline Amikacin & - & - & 1 & 2.0 & 1 & 6.7 & - & - \\
\hline Amp-Sul & 28 & 56.0 & 31 & 62.0 & 15 & 100 & 13 & 100 \\
\hline Pip-Tazo & $5^{* *}$ & $10.0^{* *}$ & 21 & 52.0 & 1 & 6.7 & 3 & 23.1 \\
\hline Ceftriaxone & 10 & 20.0 & 25 & 50.0 & NA & NA & NA & NA \\
\hline Ceftazidime & 10 & 20.0 & 25 & 50.0 & - & - & NA & NA \\
\hline Cefepime & 10 & 20.0 & 25 & 50.0 & 1 & 6.7 & 3 & 23.1 \\
\hline Cefuroxime & 12 & 24.0 & 26 & 52.0 & NA & NA & NA & NA \\
\hline Imipenem & 2 & 4.0 & 5 & 10.0 & $-\Delta \Delta$ & $-\Delta \Delta$ & 1 & 7.7 \\
\hline Meropenem & 1 & 2.0 & 5 & 10.0 & - & - & 1 & 7.7 \\
\hline Ertapenem & 1 & 2.0 & $5^{+}$ & $10.0^{+}$ & 1 & 6.7 & 2 & 15.4 \\
\hline Ciprofloxacin & 15 & 30.0 & 23 & 46.0 & $1^{\S}$ & $6.7^{\S}$ & 5 & 38.5 \\
\hline Gentamicin & $5 * * *$ & $10.0^{* * *}$ & 14 & 28.0 & - & - & 3 & 23.1 \\
\hline Polymyxin & - & - & 1 & 2.0 & $15^{\S \S}$ & $100^{\S \S}$ & 4 & 30.8 \\
\hline Tigecycline & - & - & $4^{\Delta}$ & $8.0^{\Delta}$ & $1^{\Omega}$ & $6.7^{\Omega}$ & $1 \Omega \Omega$ & $7.7^{\Omega \Omega}$ \\
\hline
\end{tabular}

${ }^{*}$ Considered resistant or intermediary profile; ${ }^{* *}$ Just 1 isolate of $E$. coli was not tested against piperacillin-tazobactam; *** Just 1 isolate of $E$. coli was not tested against gentamicin; ${ }^{+}$just 1 isolate of $K$. pneumoniae was not tested against ertapenem; ${ }^{\Delta} 7$ isolates of $K$. pneumoniae were not tested against tigecycline; ${ }^{\Delta{ }{ }} 2$ isolates of $S$. marcescens were not tested against imipenem; ${ }^{\S} 2$ isolates of S. marcescens were not tested against ciprofloxacin; ${ }^{\S \S}$. marcescens is intrinsically resistant to polymyxin; ${ }^{\Omega} 1$ isolate of $S$. marcescens were not tested against tigecycline; ${ }^{\Omega} 3$ isolates of $E$. cloacae were not tested against tigecycline; NA- Not applicable; (-) no resistant microbial isolates

Table 5 Proportions of antimicrobial resistance among non-fermentative gram-negative bacilli that were most frequently isolated from bloodstream infections

\begin{tabular}{|c|c|c|c|c|}
\hline \multirow[b]{2}{*}{ Antimicrobial drug } & \multicolumn{2}{|c|}{$\begin{array}{l}\text { Pseudomonas aeruginosa } \\
(n=12)\end{array}$} & \multicolumn{2}{|c|}{$\begin{array}{l}\text { Acinetobacter baumannii } \\
(n=6)\end{array}$} \\
\hline & No. of isolates & $\%$ resistant* & No. of isolates & $\%$ resistant $^{*}$ \\
\hline Amikacin & - & - & 1 & 16.7 \\
\hline Aztreonam & 4 & 25 & $1^{* *}$ & $16.7^{* *}$ \\
\hline Amp-Sul & NA & NA & $3^{* * *}$ & $50.0^{* * *}$ \\
\hline Pip-Tazo & 1 & 8.3 & 4 & 66.7 \\
\hline Ceftazidime & 1 & 8.3 & 4 & 66.7 \\
\hline Cefepime & - & - & 4 & 66.7 \\
\hline Imipenem & 3 & 25.0 & 4 & 66.7 \\
\hline Meropenem & 2 & 16.7 & 4 & 66.7 \\
\hline Ciprofloxacin & 1 & 8.3 & 4 & 66.7 \\
\hline Gentamicin & - & - & 2 & 33.3 \\
\hline Polymyxin & - & - & - & - \\
\hline Sulfamethoxazole trimethoprim & NA & NA & 5 & 83.4 \\
\hline Tobramycin & - & - & NA & NA \\
\hline Tigecycline & NA & NA & $-* * * *$ & $-* * * *$ \\
\hline
\end{tabular}

*Considered resistant or intermediary profile;**just 1 isolate of $A$. baumannii was tested against aztreonam;*** just 1 isolate of $A$. baumannii was not tested against ampicillin-sulbactam; *** just 1 isolate of $A$. baumannii was not tested against tigecycline; NA- Not applicable; and (-) no resistant microbial isolates 
study months. It was also observed that this profile is present in all the hospital units, with hospital wards being the units that harbored the most cases of this profile.

A similar situation was observed for the $1 \mathrm{kp}$ profile of $K$. pneumoniae $\left(b l a_{\mathrm{SHV}}, n=15\right)$. This profile was the most frequently noted among the isolates of $K$. pneumoniae, and it occurred during most months of the study period. This pattern was found in the hospital wards and semi-intensive unit, and it was predominant in the ICU setting. Unlike E. coli, no case of K. pneumoniae with resistance genes occurred in the emergency department. The ICU setting harbored a greater diversity of $K$. pneumoniae genetic profiles, albeit the profile with the highest number of resistance genes $\left(12 k p-b l a_{\mathrm{TEM}}, b l a_{\mathrm{SHV}}\right.$, $b l a_{\mathrm{OXA}-1 \text {-like, }} b l a_{\mathrm{CTX}-\mathrm{M} \text {-gp } 1}$ and $\left.b l a_{\mathrm{KPC}}\right)$ occurred in the semi-intensive unit.

\section{Discussion}

Understanding the regional epidemiological and microbiological data is of great importance when handling potentially life-threatening infections such as BSI, since accuracy in predicting pathogens and the resistance profile are crucial for successful therapy $[17,31]$. Surveillance studies focused on BSI are considered good choices for assessed issues related to antimicrobial resistance since the standardized clinical diagnostic criteria of those infections prevent the problem of confounding colonizing agents that are not directly associated with clinical disease, making the data more reliable [15].

Consistent with previous studies about the epidemiology of BSI that were undertaken inside and outside of Brazil, the majority of BSI occurred in male and elderly patients $[12,15,32,33]$. The predominance of patients of the male sex who suffered this type of infection seems to be independently associated with the age group, since it was noted not only in the elderly population, but also in studies conducted in pediatric populations [16, 17, 34].

Overall, $28.7 \%$ of patients included in the present investigation had BSI due to MDR pathogens. We found that the male sex, age $\geq 60$, previous antimicrobial therapy, liver disease and bacteremia caused by $K$. pneumoniae were independent factors associated with MDR infection. Studies of risk factors for MDR-GNB infections and/or colonization are difficult to compare since the study designs, populations, local-epidemiology, and definitions of resistance vary widely [35]. However, some investigations point to similar observations as those described here [36-38].

Regarding liver disease, there are reports relating this condition to a greater predisposition to bacterial infections, but there is little evidence of predisposition to the MDR phenotype [39]. We believe that over the course of the illness, patients with this chronic condition frequently need day hospital care, recurrent hospitalization or admission to intensive care units, which may increase the risk of acquiring MDR pathogens. Another reason which can explain this predisposition is the fact that those patients are often submitted to antimicrobial therapy (prophylactic and therapeutic) in order to prevent and to treat the recurrence of spontaneous bacterial peritonitis and other bacterial infections which are common in this subpopulation.

The previous use of antimicrobials is well-described in the literature as a risk factor for infection due to MDRGNB, especially concerning cephalosporins, carbapenems and fluoroquinolones [40]. Our findings show the predominance of fluoroquinolone use in the MDR-group, although statistical significance was not reached. We hypothesized that we could not see a statistical association because our sample was small and heterogeneous (we included all the gram-negative ones, not just one species).

It is not surprising, and it is consistent with previous reports, that $K$. pneumoniae infections showed a statistical association with the MDR phenotype. This organism is notorious for its ability to accumulate and transfer resistance determinants, and it has been well-recognized as a leading causative agent of hospital-based infections over the past few decades. The association of $K$. pneumoniae with BSI caused by MDR-GNB has already been reported in Europe, Asia, and South America [41-44].

Most studies on the epidemiology of BSIs have focused on hospital-onset infections alone. Our study examines community-onset and hospital-onset healthcareassociated infections (CO-HCA and HO-HCA) and community-acquired infections (CA), allowing us to elucidate the differences between them regarding the resistance profile and causative microorganisms. However, we had a low proportion of community-acquired cases $(n=$ $6,4.2 \%$ ), which may have been explained by the profile of the São Rafael Hospital, since most of the patients attending this institution have chronic healthcare conditions. These small numbers of cases have limited our ability to make inferences about the epidemiology of these infections.

Nevertheless, it was possible to note the HO-HCA infections harbored a greater number of MDR cases $(n=29,70.7 \%)$ compared to the CO-HCA infections ( $n=11,26.8 \%)$ and CA infections $(n=1,2.4 \%)$, which has biological plausibility since hospitals are widely recognized as environments that multiply and disseminates MDR microorganisms [45]. Regarding the etiology of $\mathrm{CA}$ and $\mathrm{CO}-\mathrm{HCA}$ infections, the most frequently noted pathogen was E. coli. The HO-HCA infections were mostly made up of $K$. pneumoniae cases, and A. baumannii was found only in this type of infection, which is consistent with previous reports $[15,17,44]$. 
The antibiotic resistance proportions found in our study are worrisome, especially regarding $K$. pneumoniae, which was the Enterobacteriaceae with the highest resistance level, at $52.0 \%$ to cephalosporins and $10.0 \%$ to carbapenems, and A.baumannii, which presented 66.7\% to cephalosporins and carbapenems and $83.4 \%$ to sulfametoxazole-trimethoprim. Our data is consistent with those described by Marra et al. [15] that evaluated the epidemiology of nosocomial BSI from a prospective nationwide surveillance study. This data came from hospitals geographically dispersed throughout the five different regions of Brazil, suggesting the important external validity of our study.

In contrast to the Brazilian scientific literature data on the emergence of $\beta$-lactamases [41, 45], which shows that cefotaximases are the most detected $\beta$-lactamase, especially CTX-M-gp2, the most frequent resistance determinants in our evaluation were bla $a_{\mathrm{SHV}}(n=42)$ and bla $_{\text {TEM }}(n=37)$, followed by bla OXA-1-like $(n=22)$, bla $_{\text {CTX-M-gp1 }} \quad(n=22), \quad b l a_{\text {СТХ-M-gp9 }} \quad(n=4)$ and bla $_{\text {CTX-M-gp2 }}(n=1)$. However, K.pneumoniae was the microbial species with the highest prevalence of resistance genes $(74.0 \%)$, which is concordant with previous findings [38]. It is worth mentioning that, albeit we have few isolates from CA infections, half of them presented $\beta$-lactamases genes (bla $a_{\mathrm{TEM}}, b l a_{\mathrm{SHV}}$, and $\left.b l a_{\mathrm{CTX}-\mathrm{M} \text {-gp9 }}\right)$, demonstrating the spread of these genes in off-hospital environments.

Concerning the carbapenemase genetic determinants, the $b l a_{\mathrm{KPC}}$ was the most frequently noted,

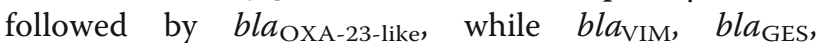
$b l a_{\mathrm{OXA}-48-\text { like, }}$ and $b l a_{\mathrm{NDM}}$ were the least frequently noted. In Latin America, Brazil stands out as one of the countries in which carbapenemases are most frequently reported. The $b l a_{\mathrm{KPC}}$ gene is widely distributed throughout the country and its occurrence was already described in $K$. pneumoniae, Enterobacter spp., E. coli, S. marcescens, and K. oxytoca clinical isolates [46]. Recently, Tavares et al. [47] reported the presence of the KPC-2 gene in the state of Bahia for the first time, in E. coli isolates. In our study $4 / 5$ $(80 \%)$ of KPC producers were $K$. pneumoniae isolates, whereas $20 \%$ were E.coli.

The first clinical report of $b l a_{\mathrm{NDM}}$ in northeast Brazil was in a public hospital in Salvador, recently described by Barberino et al. [48]. In our investigation, the presence of the bla $a_{\mathrm{NDM}}$ gene was verified in an $E$. coli isolate; however this strain did not express phenotypic resistance to carbapenems.

The present study has the major advantage of being prospective, with a clear and consensual definition of infection. However, it also has significant limitations that should be acknowledged. Cases in which bacterial isolates were not stored were not included in this investigation. Furthermore, even though, this evaluation corresponds to the beginning of a surveillance network to track antimicrobial resistance in hospitals in the city of Salvador, our analyses reflect the profile of only one institution. Therefore, they cannot be extrapolated to the general population or applied to the situations of other hospitals. Nevertheless, the results presented here constitute the first step for future multicenter studies focusing on avoid the dissemination of the resistance genes in the region of Salvador.

\section{Conclusions}

In summary, we found that the factors associated with MDR bacteremia were liver disease, male sex, age $\geq 60$, previous therapeutic antimicrobial use and bacteremia caused by K. pneumoniae. Regarding resistance determinants, SHV, TEM, OXA-1-like and CTX-M-gp1 were the predominant enzymatic variants, whereas CTX-Mgp9, CTX-M-gp2, KPC, VIM, GES, OXA-48-like, NDM and OXA-23-like can be characterized as emerging enzymes.

\section{Additional files}

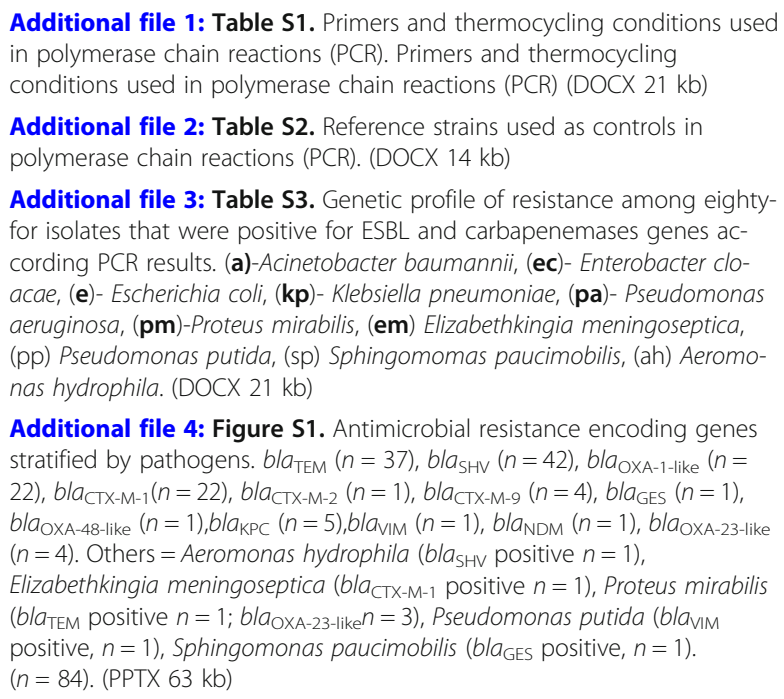

Additional file 1: Table S1. Primers and thermocycling conditions used in polymerase chain reactions (PCR). Primers and thermocycling conditions used in polymerase chain reactions (PCR) (DOCX $21 \mathrm{~kb}$ )

Additional file 2: Table S2. Reference strains used as controls in polymerase chain reactions (PCR). (DOCX 14 kb)

Additional file 3: Table S3. Genetic profile of resistance among eightyfor isolates that were positive for ESBL and carbapenemases genes according PCR results. (a)-Acinetobacter baumannii, (ec)- Enterobacter cloacae, (e)- Escherichia coli, (kp)- Klebsiella pneumoniae, (pa)- Pseudomonas aeruginosa, (pm)-Proteus mirabilis, (em) Elizabethkingia meningoseptica, (pp) Pseudomonas putida, (sp) Sphingomomas paucimobilis, (ah) Aeromonas hydrophila. (DOCX $21 \mathrm{~kb}$ )

Additional file 4: Figure S1. Antimicrobial resistance encoding genes stratified by pathogens. bla $a_{\mathrm{TEM}}(n=37)$, bla $a_{\mathrm{SHV}}(n=42)$, bla $a_{\mathrm{OXA}-1 \text {-like }}(n=$ $22)$, bla $a_{\mathrm{CTX}-\mathrm{M}-1}(n=22)$, bla $a_{\mathrm{CTX}-\mathrm{M}-2}(n=1)$, bla $a_{\mathrm{CTX}-\mathrm{M}-9}(n=4)$, bla $a_{\mathrm{GES}}(n=1)$, bla OXA-48-like $(n=1)$, bla $a_{\mathrm{KPC}}(n=5)$, bla $\mathrm{VIM}(n=1)$, bla $a_{\mathrm{NDM}}(n=1)$, bla OXA-23-like $(n=4)$. Others = Aeromonas hydrophila (bla $a_{\text {SHv }}$ positive $\left.n=1\right)$,

Elizabethkingia meningoseptica (bla $a_{\mathrm{CTX}-\mathrm{M}-1}$ positive $n=1$ ), Proteus mirabilis (bla TEM positive $n=1$; bla $a_{\text {OXA-23-like }} n=3$ ), Pseudomonas putida (bla $a_{\mathrm{VIM}}$ positive, $n=1)$, Sphingomonas paucimobilis (bla GES $_{\text {positive, } n=1)}$. $(n=84)$. (PPTX $63 \mathrm{~kb})$

\section{Abbreviations}

${ }^{\circ} \mathrm{C}$ : Degree Celsius; bla: $\beta$-lactamase; BSI: Bloodstream Infection;

CA: Community-acquired bloodstream infection; CDC: Centers of Disease Control and Prevention; CLSI: Clinical and Laboratory Standards Institute; COHCA: Community-onset, healthcare-associate bloodstream infection; CTX-Mgp1: Cefotaximases group 1; CTX-M-gp2: Cefotaximases group 2; CTX-Mgp9: Cefotaximases group 9; ES $\beta$ L: Extended Spectrum $\beta$-lactamase; Fiocruz: Fundação Oswaldo Cruz; HO-HCA: Hospital-onset, healthcareassociated bloodstream infection; HSR: Hospital São Rafael; M: Molar; MALDITOF/MS: Matrix-Assisted Laser Desorption Ionization-Time of Flight/ Mass Spectrometry; MDR: multidrug resistance; mg: Milligram; mL: Milliliter; mM: Millimolar; pH: Hydrogen potential; $\mu \mathrm{g}$ : Microgram; $\mu \mathrm{L}$ : Microliter; SIRS: Systemic Inflammatory Response Syndrome; SUS: Sistema Único de Saúde; TBE: Tris-Borate-EDTA; pmol: picomol 


\section{Acknowledgments}

We would like to thank the teams at the Laboratory of Microbiology and the Infection Control Committee from Hospital São Rafael for all their logistical support in the storage and collection of the bacterial isolates as well as for providing the physical structure for the reviewing of medical records. We are grateful to the staff at the Laboratory of Research in Medical Microbiology (LIMM) at the Federal University of Rio de Janeiro (UFRJ) and to Professor Renata Cristina Picão for kindly donating the reference strains used in this study. We are equally grateful to the team at the Special Laboratory of Clinical Microbiology (LEMC) and the Laboratory ALERTA of the Federal University of São Paulo (UNIFESP), which was coordinated by Ana Cristina Gales and to Lorena Fehlberg for also collaborating with the donation of reference strains for this work. The information presented here has been partially exhibited in the "Brazilian Congress of Infectology 2017". Nevertheless, the results shown did not compromise the originality of this paper

\section{Authors' contributions}

"HFL" contributed with the conceptualization of the research project and its methodology; collected clinical and epidemiological information thought medical records review; performed the microbiological and molecular tests; analyzed and interpreted data; wrote (original draft preparation); and reviewed and edited the manuscript. "JA" and "ELG" contributed with the conceptualization of the research project and its methodology; analyzed and interpreted data; and reviewed and edited the manuscript. "GEODS", "AMLM", "LCR" and "ACPA" performed the microbiological and molecular tests; and reviewed and edited the manuscript. "MGR", AVM", "MSO", "MGB" and "ISM" contributed with the conceptualization of the research project and its methodology; and reviewed and edited the manuscript. "JNR" contributed with the conceptualization of the research project and its methodology; was responsible for the project administration and supervised the procedures carried out in this research; analyzed and interpreted data; reviewed and edited the manuscript. All authors have read and approved the final manuscript.

\section{Funding}

Fundação de Amparo à Pesquisa do Estado da Bahia (FAPESB) /PP-SUS 0024/ 2014.Instituto Nacional de Pesquisa em Resistência Antimicrobiana (INPRA), CNPq 465718/2014-0, FAPERGS 17/2551-0000514-7. Leal, HF was a recipient of a fellowship from Foundation for Research Support of the State of Bahia (FAPESB - Brazil). The Funders had no role in the study design, data collection and analysis, decision to publish or manuscript preparation.

\section{Availability of data and materials}

The datasets used in the current study are not publicly available to maintain the privacy and confidentiality of the participants but are available from the corresponding author on reasonable request.

\section{Ethics approval and consent to participate}

Ethics clearance was obtained from the Research Ethics Committee of the Nursing School of Federal University of Bahia (UFBA) (655.681), and the Medical Board and Ethics Committee of the São Rafael Hospital (2.415.920). The Medical Board and Ethics Committee of the São Rafael Hospital provided ethical clearance for conducting this study and waivered the requirement to obtain informed consent from the patients whose medical records were analyzed in this study, as its involved an internal, retrospective review of patient charts without any acquisition of identifying patient information. Permission was obtained from the Medical Board and Ethics Committee of the São Rafael Hospital to review patient charts. Data were accessible only to authorized members of the core study team.

\section{Consent for publication}

Not applicable.

\section{Competing interests}

The authors declare that they have no competing interests. JNR is an Editorial Board Member in BMC Infectious Diseases.

\section{Author details}

'Laboratory of Pathology and Molecular Biology (LPBM), Gonçalo Moniz Research Institute, Oswaldo Cruz Foundation, Candeal, Salvador, Bahia
40296-710, Brazil. ²Laboratory of Research on Clinical Microbiology (LPMC), School of Pharmacy, Federal University of Bahia, Ondina, Salvador, Bahia 40170-115, Brazil. ${ }^{3}$ São Rafael Hospital, São Marcos, Salvador, Bahia 41253-190, Brazil. "Bahia Hospital, Pituba, Salvador, Bahia 40280-000, Brazil. ${ }^{5}$ Bahiana School of Medicine and Public Health of the Bahia Foundation for the Development of Sciences, Salvador, Bahia, Brazil. ${ }^{6}$ Faculty of Medicine, Fluminense Federal University Downtown, 24033-900, Niterói, Rio de Janeiro, Brazil.

Received: 23 January 2019 Accepted: 5 July 2019

Published online: 11 July 2019

\section{References}

1. Loonen AJM, de Jager CPC, Tosserams J, et al. Biomarkers and molecular analysis to improve bloodstream infection diagnostics in an emergency care unit. PLoS One. 2014;9:e87315.

2. Cohen J, Vincent JL, Adhikari NKJ, et al. Sepsis: a roadmap for future research. Lancet Infect Dis. 2015;15:581-614.

3. Geneva. Misdiagnosed 'sepsis' now a global health priority for World Health Organization. 2017. Available at: https://www.global-sepsis-alliance.org/s/ WHA-Adopts-Resolution-on-Sepsis.pdf. Accessed 30 May 2017.

4. Singer M, Deutschman CS, Seymour CW, et al. The third international consensus definitions for sepsis and septic shock (sepsis-3). JAMA. 2016; 315:801-10

5. Liu V, Escobar GJ, Greene JD, et al. Hospital deaths in patients with sepsis from 2 independent cohorts. JAMA. 2014;312:90-2

6. Rhodes A, Evans LE, Alhazzani W, et al. Surviving sepsis campaign: international guidelines for management of sepsis and septic shock: 2016. Intensive Care Med. 2017;43:304-77.

7. Kumar A, Ellis $P$, Arabi $Y$, et al. Initiation of inappropriate antimicrobial. therapy results in a fivefold reduction of survival in human septic shock. Chest J. 2009;136:1237-48.

8. Buehler SS, Madison B, Snyder SR, et al. Effectiveness of practices to increase timeliness of providing targeted therapy for inpatients with bloodstream infections: a laboratory medicine best practices systematic review and meta-analysis. Clin Microbiol Rev. 2016;29:59-103.

9. Johnson AP, Ashiru-Oredope D, Beech E. Antibiotic stewardship initiatives as part of the UK 5-year antimicrobial resistance strategy. Antibiotics. 2015;4:467-79.

10. Johnson AP. Improving antimicrobial stewardship: AmWeb, a tool for helping microbiologists in England to "Start Smart" when advising on antibiotic treatment. J Antimicrob Chemother. 2013;68:2181-2 https:// academic.oup.com/jac/article-lookup/doi/10.1093/jac/dkt216. Accessed 25 June 2017.

11. Goff DA, et al. A global call from five countries to collaborate in antibiotic stewardship: united we succeed, divided we might fail. Lancet Infect Dis. 2017;17(2):e56-63.

12. Anderson DJ, Moehring RW, Sloane R, et al. Bloodstream infections in community hospitals in the 21st century: A Multicenter Cohort Study. PLOS ONE PlanetPJ, ed. 2014; 9:e91713.

13. Laupland KB, Church DL. Population-based epidemiology and microbiology of community-onset bloodstream infections. Clin Microbiol Rev. 2014;27:647-64.

14. Larru B, Gong W, Vendetti N, et al. Bloodstream infections in hospitalized children: epidemiology and antimicrobial susceptibilities. Pediatr Infect Dis J. 2016;35:507-10.

15. Marra AR, Camargo LFA, Pignatari ACC, et al. Nosocomial bloodstream infections in Brazilian hospitals: analysis of 2,563 cases from a prospective nationwide surveillance study. J Clin Microbiol. 2011:49:1866-71.

16. Villegas MV, et al. Characterization and clinical impact of bloodstream infection caused by carbapenemase-producing Enterobacteriaceae in seven Latin American countries. PLoS One. 2016;11(4):e0154092.

17. Pereira CAP, Marra AR, Camargo LFA, et al. Nosocomial bloodstream infections in Brazilian pediatric patients: microbiology, epidemiology, and clinical features. PLoS One. 2013;8:e68144.

18. Kahlmeter G, Brown AFJ. Resistance surveillance studies - comparability of results and quality assurance of methods. J Antimicrob Chemother. 2002;50:775-7.

19. Charlson ME, Pompei P, Ales KL, MacKenzie CR. A new method of classifying prognostic comorbidity in longitudinal studies: development and validation. J Chronic Dis. 1987;40:373-83. 
20. Chow JW, Victor LY. Combination antibiotic therapy versus monotherapy for gram-negative bacteraemia: a commentary. Int J of Antimicrob Agents. 1999;11(1):7-12.

21. Klevens RM, et al. Invasive methicillin-resistant Staphylococcus aureus infections in the United States. Jama. 2007;298(15):1763-71.

22. ANVISA, Brasília DF. Manual de definição dos critérios nacionais de infecções de corrente sanguínea relacionadas à assistência à saúde. 2009.

23. Safety P. National Healthcare Safety Network (NHSN) Overview. Available at: https://www.cdc.gov/nhsn/pdfs/pscmanual/1psc_overviewcurrent.pdf. Accessed 25 June 2017.

24. Bone RC, Balk RA, Cerra FB, et al. Definitions for sepsis and organ failure and guidelines for the use of innovative therapies in sepsis. Chest. 1992;101: 1644-55.

25. Levy MM, Fink MP, et al. 2001 SCCM/ESICM/ACCP/ATS/SIS international Sepsis definitions conference. Intensive Care Med. 2003;29:530-8.

26. Magiorakos AP, Srinivasan A, Carey RB, et al. Multidrug-resistant, extensively drug-resistant and pandrug-resistant bacteria: an international expert proposal for interim standard definitions for acquired resistance. Clin Microbiol Infect. 2012;18:268-81.

27. Barberino MG, de Silva MO, Arraes ACP, Correia LC, Mendes AV. Direct identification from positive blood broth culture by matrix-assisted laser desorption-ionization time-of-flight mass spectrometry (MALDI-TOF MS). Braz J Infect Dis. 2017;21:339-42.

28. Patel JB. Approved Guideline, M-02 e M-07. Clinical and Laboratory Standards Institute. Performance Standards for Antimicrobial Susceptibility Testing MS100-26. 2016.

29. Dallenne C, Da Costa A, Decré D, Favier C, Arlet G. Development of a set of multiplex PCR assays for the detection of genes encoding important $\beta$ lactamases in Enterobacteriaceae. J Antimicrob Chemother. 2010;65:490-5.

30. van der Zwaluw K, de Haan A, Pluister GN, Bootsma HJ, de Neeling AJ, Schouls LM. The carbapenem inactivation method (CIM), a simple and lowcost alternative for the Carba NP test to assess phenotypic carbapenemase activity in gram-negative rods. PLoS One. 2015;10:e0123690.

31. Thaden JT, Park LP, Maskarinec SA, Ruffin F, Fowler VG, van Duin D. Results from a 13-year prospective cohort study show increased mortality associated with bloodstream infections caused by Pseudomonas aeruginosa compared to other bacteria. Antimicrob Agents Chemother. 2017;61:e02671-16.

32. Aung AK, Skinner MJ, Lee FJ, Cheng AC. Changing epidemiology of bloodstream infection pathogens over time in adult non-specialty patients at an Australian tertiary hospital. Commun Dis Intell Q Rep. 2012;36:E333-41.

33. da Rocha JA, do Valle FM, da Silva NCZ, et al. Disability adjusted life year (Daly) of central-line bloodstream infection (CLABSI) in a university hospital in a developing country, Brazil. Infect Control Hosp Epidemiol. 2017:38:606-9.

34. Buetti N, Atkinson A, Kottanattu $L$, et al. Patterns and trends of pediatric bloodstream infections: a 7-year surveillance study. Eur J Clin Microbiol Infect Dis. 2017;36:537-44.

35. Patel SJ, Oliveira AP, Zhou JJ, et al. Risk factors and outcomes of infections caused by extremely drug-resistant gram-negative bacilli in patients hospitalized in intensive care units. Am J Infect Control. 2014;42:626-31.

36. Cardoso T, Ribeiro O, Aragão IC, Costa-Pereira A, Sarmento AE. Additional risk factors for infection by multidrug-resistant pathogens in healthcareassociated infection: a large cohort study. BMC Infect Dis. 2012;12:375.

37. Pop-Vicas AE, D'agata EM. The rising influx of multidrug-resistant gramnegative bacilli into a tertiary care hospital. Clin Infect Dis. 2005;40:1792-8.

38. Aliyu S, Smaldone A, Larson E. Prevalence of multidrug-resistant gramnegative bacteria among nursing home residents: A systematic review and meta-analysis. Am J Infect Control. 2017;45:512-8.

39. Merli M, Lucidi C. Bacterial resistance in cirrhotic patients: an emerging reality. J Hepatol. 2012;56:756-7.

40. Orsi GB, Falcone M, Venditti M. Surveillance and management of multidrugresistant microorganisms. Expert Rev Anti-Infect Ther. 2011;9:653-79.

41. Sampaio JLM, Gales AC. Antimicrobial resistance in Enterobacteriaceae in Brazil: focus on $\beta$-lactams and polymyxins. Braz J Microbiol. 2016:47:31-7.

42. Orsi GB, et al. Changed epidemiology of ICU acquired bloodstream infections over 12 years in an Italian teaching hospital. Minerva Anestesiol. 2015;81:980-8

43. Gupta A, Sharma S, Arora A, Gupta A. Changing trends of in vitro antimicrobial resistance patterns in blood isolates in a tertiary care hospital over a period of 4 years. Indian J Med Sci. 2010;64:485-92.
44. Bonelli RR, Moreira BM, Picão RC. Antimicrobial resistance among Enterobacteriaceae in South America: history, current dissemination status and associated socioeconomic factors. Drug Resist Updat. 2014;17:24-36.

45. Orsi GB, Franchi C, Giordano A, Rocco M, Ferraro F, Mancini C, Venditti M. Multidrug resistant Acinetobacter baumannii in an intensive care unit. J Chemother. 2008;20:219-24.

46. Escandon-Vargas K, et al. The epidemiology of carbapenemases in Latin America and the Caribbean. Expert Rev Anti-Infect Ther. 2017;15(3):277-97.

47. Tavares CP, Pereira PS, Marques Ede A, et al. Molecular epidemiology of KPC-2-producing Enterobacteriaceae (non-Klebsiella pneumoniae) isolated from Brazil. Diagn Microbiol Infect Dis. 2015;82:326-30.

48. Barberino MG, Cruvinel SA, Faria C, et al. Isolation of blaNDM-producing Enterobacteriaceae in a public hospital in Salvador, Bahia, Brazil. Braz J Infect Dis. 2018;22:47-50

\section{Publisher's Note}

Springer Nature remains neutral with regard to jurisdictional claims in published maps and institutional affiliations.

\section{Ready to submit your research? Choose BMC and benefit from:}

- fast, convenient online submission

- thorough peer review by experienced researchers in your field

- rapid publication on acceptance

- support for research data, including large and complex data types

- gold Open Access which fosters wider collaboration and increased citations

- maximum visibility for your research: over $100 \mathrm{M}$ website views per year

At $\mathrm{BMC}$, research is always in progress.

Learn more biomedcentral.com/submissions 